University of Nebraska - Lincoln

DigitalCommons@University of Nebraska - Lincoln

Faculty Papers and Publications in Animal

Science

Animal Science Department

June 2007

\title{
Effect of competition on gain in feedlot bulls from Hereford selection lines
}

\author{
L. Dale Van Vleck \\ University of Nebraska-Lincoln, dvan-vleck1@unl.edu
}

L. V. Cundiff

Roman L. Hruska US Meat Animal Research Center, Clay Center, NE

R. M. Koch

University of Nebraska-Lincoln, rkoch1@unl.edu

Follow this and additional works at: https://digitalcommons.unl.edu/animalscifacpub

Part of the Animal Sciences Commons

Van Vleck, L. Dale; Cundiff, L. V.; and Koch, R. M., "Effect of competition on gain in feedlot bulls from Hereford selection lines" (2007). Faculty Papers and Publications in Animal Science. 123.

https://digitalcommons.unl.edu/animalscifacpub/123

This Article is brought to you for free and open access by the Animal Science Department at DigitalCommons@University of Nebraska - Lincoln. It has been accepted for inclusion in Faculty Papers and Publications in Animal Science by an authorized administrator of DigitalCommons@University of Nebraska - Lincoln. 


\title{
Effect of competition on gain in feedlot bulls from Hereford selection lines ${ }^{1}$
}

\author{
L. D. Van Vleck, ${ }^{*} \dagger^{2}$ L. V. Cundiff, $*$ and R. M. Koch $\dagger$ \\ *Roman L. Hruska US Meat Animal Research Center, Clay Center, NE 68933; and \\ $\dagger$ Department of Animal Science, University of Nebraska, Lincoln 68583-0908
}

\begin{abstract}
This study examined competition effects on ADG in the feedlot of 1,882 Hereford bulls representing 8 birth years from a selection experiment. Each year, 8 feedlot pens were used to feed bulls in groups, with 2 pens nested within each of the 4 selection lines. Gains were recorded for up to 8 periods of 28 d. Models for analyses included pen effects (fixed or random), fixed effects such as year and line, and random direct genetic, competition genetic (and in some analyses competition environmental), and environmental effects. Each pen mate as a competitor affected the records of all others in the pen. All lines traced to common foundation animals, so the numerator relationships among and within pens were the bases for separating direct and competition genetic effects and pen effects.
\end{abstract}

For this population and pen conditions (average of 30 bulls per pen), the major results were 1) competition genetic effects seemed present for the first 28-d period but not for the following 7 periods; 2) models with pens considered as fixed effects could not separate variances and covariance due to direct and competition genetic effects; 3) models without competition effects had large estimates of the variance component due to pen effects for gain through 8 periods; and 4) models with genetic and environmental competition effects accounted for nearly all of the variance traditionally attributed to pen effects (even though estimates of the competition variance component were small, the estimates of pen variance were near zero).

Key words: average daily gain, beef cattle, competition effect, genetic effect

(2007 American Society of Animal Science. All rights reserved.

J. Anim. Sci. 2007. 85:1625-1633 doi:10.2527/jas.2007-0067

\section{INTRODUCTION}

Muir and Schinckel (2002) introduced the prediction of direct and competition (associative) genetic effects for animals. Earlier, Federer (1955) had discussed competition effects for plants and animals. Griffing (1967) developed a theory for accounting for direct and associative effects for plants. Van Vleck and Cassady (2005) reported results from analyses of data simulated from models that included direct and competition genetic effects. For ADG of Large White gilts housed in pens, Arango et al. (2005) attempted to estimate variance components associated with pen mates. They reported for their data structure and large pen sizes that accurate estimation of parameters for competition effects was not possible.

The purpose of this study was to estimate variance and (co)variance components for direct and competition

\footnotetext{
${ }^{1}$ The authors express appreciation to Darrell Light for data base support and to Donna White for secretarial support in preparation of this manuscript.

${ }^{2}$ Corresponding author: lvanvleck@unlnotes.unl.edu

Received January 26, 2007.

Accepted March 12, 2007.
}

effects for ADG for 8 time periods for Hereford bulls from 3 selection lines and 1 control line (Koch, et al., 1974a,b, 1994). An added goal was to document problems with such analyses with different statistical models.

\section{MATERIALS AND METHODS}

Animal Care and Use Committee approval was not obtained for this study because the data were obtained from an existing database recorded before an Animal Care and Use Committee was established at the US Meat Animal Research Center.

Koch et al. (1974a,b) described the foundation Herefords and methods of selection beginning in 1963 for the 3 selection lines and 1 control line. The selection lines were selected for 1) weaning BW, 2) yearling BW, and 3) an index with equal weighting for yearling BW and muscle score. For line 3, a phenotypic index was used. For each year, yearling BW divided by the yearsex phenotypic SD for yearling BW was added to the muscle score divided by the year-sex phenotypic SD for muscle score. The control line was created using foundation sires and foundation dams of the selected lines. The foundation lines were created from related 
Table 1. Unadjusted means for initial BW $(\mathrm{kg})$ and ADG $(\mathrm{kg} \times 100)$ through periods 1 through 8 by year of birth (1972-1979)

\begin{tabular}{|c|c|c|c|c|c|c|c|c|c|c|}
\hline \multirow{2}{*}{$\begin{array}{l}\text { Year } \\
\text { born }\end{array}$} & \multirow[b]{2}{*}{ No. ${ }^{1}$} & \multirow{2}{*}{$\begin{array}{c}\text { Initial } \\
\text { BW }\end{array}$} & \multicolumn{8}{|c|}{ Period } \\
\hline & & & 1 & 2 & 3 & 4 & 5 & 6 & 7 & 8 \\
\hline 1972 & 245 & 221 & 32 & 92 & 86 & 85 & 91 & 82 & 87 & 87 \\
\hline 1973 & 211 & 213 & 84 & 95 & 103 & 109 & 112 & 115 & 115 & - \\
\hline 1974 & 235 & 172 & 94 & 90 & 79 & 87 & 85 & 91 & 90 & 94 \\
\hline 1975 & 230 & 219 & 124 & 125 & 131 & 132 & 128 & 129 & - & - \\
\hline 1976 & 227 & 241 & 124 & 123 & 123 & 122 & 119 & 117 & 116 & - \\
\hline 1977 & 254 & 230 & 111 & 95 & 103 & 105 & 109 & 109 & 109 & - \\
\hline 1978 & 236 & 222 & 102 & 109 & 109 & 109 & 109 & 112 & 112 & 111 \\
\hline 1979 & 244 & 220 & 130 & 113 & 118 & 116 & 116 & 112 & 113 & 110 \\
\hline Total No. & 1,882 & 1,882 & 1,876 & 1,874 & 1,867 & 1,866 & 1,864 & 1,863 & 1,634 & 946 \\
\hline
\end{tabular}

${ }^{1}$ Number with an initial BW observation.

animals, so that the numerator relationships across lines and within lines were available to attempt to separate components of variance due to direct and competition genetic effects and due to pen effects.

This analysis involved bull calves born in the 3 selection lines and the control line from 1972 to 1979. Koch et al. (1994) described management of these bulls from birth to an average age of $400 \mathrm{~d}$. During the postweaning period, bulls from each line were split into 2 randomly assigned replicate pens, with progeny of sires cross-classified with pens, and were fed a mixed diet of corn silage, rolled corn, and a protein mineral supplement, containing approximately $2.69 \mathrm{Mcal}$ of $\mathrm{ME} / \mathrm{kg}$ of $\mathrm{DM}$ and $12.88 \% \mathrm{CP}$. The ADG were calculated from initial BW on test and BW at 7 intervals of $28 \mathrm{~d}$ plus a shorter eighth interval. The number of bulls per pen varied with the number of bulls available per line each year, but ranged from approximately 25 to 30 head per pen.

The 8 pens, each measuring $15.4 \mathrm{~m}$ in width (west to east) and $61 \mathrm{~m}$ in length (south to north), were situated adjacent to each other and ran contiguously for 123.4 $\mathrm{m}$. The pens sloped gently $(2.7 \%)$ from front (south) to back (north) and even more gradually from east to west (0.6\% slope at front and $0.9 \%$ at back). Mounds of dirt measuring approximately $1 \mathrm{~m}$ in depth at their center and running south to north for approximately $40 \mathrm{~m}$ were situated in the center of each pen to provide relatively dry resting areas. At the north end of each lot, gates accessed a working alley measuring $3.75 \mathrm{~m}$ in width. Continuous fence line feed bunks running the full width (15.4 m, which was considered adequate for 33 head) were situated at the front of each pen. Automatic water troughs (heated in the winter months) were located in the fence line approximately $8.6 \mathrm{~m}$ from the feed bunk in each pen. A concrete slab extending $3 \mathrm{~m}$ from the feed bunk and around each water source was provided in each pen. A wind break composed of 3 rows of cedar trees was located approximately $12 \mathrm{~m}$ from the north fence line. No shade was provided.

The numbers of bulls by year and unadjusted mean ADG for periods 1 through 8 (ADG1 through ADG8) are shown in Table 1 along with the initial BW. The total number of bulls with initial BW was 1,882 and ranged from 211 to 254 for each year. Those means and numbers are given in Table 1. Table 1 also shows that for $4 \mathrm{yr}$, the BW were not available for period 8 and that BW were not available for period 7 for bulls born in 1975. Fixed effects in the models included linear covariates for day of year of birth, the number of competitors, and the initial BW (some analyses), as well as fixed factors of year of birth (8 levels; 1972 to 1979) and selection line (4 levels; 1, 2, 3, and control) for some analyses. Pens (up to 64) were considered to be random factors for some analyses and to be fixed factors for other analyses and were ignored in some analyses.

Table 2 (left side) describes the combinations of fixed and random factors used in 18 exploratory analyses. Random factors included direct and competition genetic effects (with and without covariance), pen effects (when not ignored or considered a fixed factor), and residual effects. Later analyses also included repeated environmental effects of competitors, as not only the competition genetic effect but also the competition environmental effect of a pen mate would be expressed in the records of all other pen mates. Modification of the MTDFREML programs (Boldman et al., 1995) has been described by Van Vleck and Cassady (2004a) for including multiple competition genetic effects. A similar modification was made to include the competition environmental effects in the model, which would be comparable to permanent environmental effects affecting all pen mates of a competitor. The unique feature of competition models is that a factor (e.g., competition genetic) may have many levels of that factor (all competitors) expressed in the record of a pen mate. Those many levels create blocks of nonzero values in the coefficient matrix for the mixed model equations, so that the coefficient matrix is less sparse than for most sets of mixed model equations.

A statistical description of an observation on animal, $\mathrm{i}$, in pen, $\mathrm{k}$, for the model with competition genetic effects is as follows: 
Table 2. Log likelihoods $(-2 \log \mathrm{L}-5,000)$ for 18 models for 9 traits $^{1}$

\begin{tabular}{|c|c|c|c|c|c|c|c|c|c|c|c|c|c|c|}
\hline \multicolumn{6}{|c|}{ Model $^{2}$} & \multirow{2}{*}{\multicolumn{9}{|c|}{ Period }} \\
\hline & & & & lom & & & & & & & & & & \\
\hline - & - & $\mathrm{D}$ & - & - & - & $9,362.78$ & $9,552.75$ & $7,724.90$ & $6,831.32$ & $6,442.63$ & $6,253.61$ & $6,040.23$ & $4,713.93$ & 512.61 \\
\hline - & - & $\mathrm{D}$ & $\mathrm{C}$ & - & - & $9,362.78$ & $9,443.74$ & $7,638.78$ & $6,760.17$ & $6,410.98$ & $6,224.43$ & $6,006.88$ & $4,638.39$ & 498.04 \\
\hline - & - & $\mathrm{D}$ & $\mathrm{C}$ & $\mathrm{R}$ & - & $9,360.04$ & $9,442.68$ & $7,635.70$ & $6,758.46$ & $6,410.20$ & $6,222.83$ & $6,005.55$ & $4,636.17$ & 496.19 \\
\hline - & - & $\mathrm{D}$ & $\mathrm{C}$ & $\mathrm{R}$ & $\mathrm{P}$ & $9,360.04$ & $9,442.68$ & $7,627.74$ & $6,754.87$ & $6,406.43$ & $6,221.46$ & $6,004.21$ & $4,634.38$ & 495.50 \\
\hline - & $\mathrm{P}$ & $\mathrm{D}$ & - & - & - & $9,107.52$ & $9,097.48$ & $7,333.63$ & $6,491.06$ & $6,167.91$ & $5,990.64$ & $5,779.27$ & $4,415.05$ & 377.41 \\
\hline - & $\mathrm{P}$ & $\mathrm{D}$ & $\mathrm{C}$ & - & - & $9,107.52$ & $9,097.48$ & 7,333.63 & $6,491.06$ & $6,167.91$ & $5,990.64$ & $5,779.27$ & $4,415.05$ & 377.42 \\
\hline - & $\mathrm{P}$ & $\mathrm{D}$ & $\mathrm{C}$ & $\mathrm{R}$ & - & $9,107.52$ & $9,097.48$ & $7,333.63$ & $6,491.06$ & $6,167.91$ & $5,990.64$ & $5,779.27$ & $4,415.05$ & 377.41 \\
\hline I & - & $\mathrm{D}$ & - & - & - & - & $9,519.92$ & $7,654.93$ & $6,768.12$ & $6,392.97$ & $6,215.93$ & $5,997.36$ & $4,675.80$ & 487.96 \\
\hline I & - & $\mathrm{D}$ & $\mathrm{C}$ & - & - & - & $9,406.40$ & $7,556.79$ & $6,688.74$ & $6,356.48$ & $6,184.50$ & $5,960.73$ & $4,592.87$ & 474.74 \\
\hline I & $\mathrm{P}$ & $\mathrm{D}$ & - & - & - & - & $9,060.25$ & $7,250.47$ & $6,419.59$ & $6,113.53$ & $5,951.52$ & $5,733.66$ & $4,368.88$ & 355.14 \\
\hline I & $\mathrm{P}$ & $\mathrm{D}$ & $\mathrm{C}$ & - & - & - & $9,060.25$ & $7,250.47$ & $6,419.60$ & $6,113.53$ & $5,951.52$ & $5,733.65$ & $4,368.88$ & 355.02 \\
\hline I & $\mathrm{P}$ & $\mathrm{D}$ & $\mathrm{C}$ & $\mathrm{R}$ & - & - & $9,060.25$ & $7,250.47$ & $6,419.60$ & $6,113.53$ & $5,951.52$ & $5,733.65$ & $4,368.88$ & 355.02 \\
\hline
\end{tabular}

${ }^{1}$ Initial $\mathrm{BW}=0$; ADG through the end of periods 1 through 8 after initial BW.

${ }^{2} \mathrm{~A}$ letter in the columns for model indicates that the effect was in the model, whereas a dash indicates that the effect was not in the model; $\mathrm{I}=$ covariate for initial BW, $\mathrm{P}($ Fixed column) = fixed pen effect, $\mathrm{D}=$ direct genetic effect, $\mathrm{C}=$ competition genetic effect, $\mathrm{R}=$ covariance between $\mathrm{D}$ and $\mathrm{C}, \mathrm{P}$ (Random column) = random pen effect.

$$
\mathrm{y}_{\mathrm{ik}}=\mu+\mathrm{b}_{\mathrm{w}} \mathrm{W}_{\mathrm{i}}+\mathrm{b}_{\mathrm{f}} \mathrm{F}_{\mathrm{i}}+\mathrm{a}_{\mathrm{i}}+\mathrm{c}_{\mathrm{k}_{1}}+\ldots+\mathrm{c}_{\mathrm{k}_{\mathrm{N}}}+\mathrm{p}_{\mathrm{k}}+\mathrm{e}_{\mathrm{ik}}
$$

where $\mathrm{y}_{\mathrm{ik}}$ is the observation, $\mu$ represents a fixed effect common to all animals, $\mathrm{b}_{\mathrm{w}} \mathrm{W}_{\mathrm{i}}$ is the product of the regression coefficient and covariate for initial BW for animal $i, b_{f} F_{i}$ is the product of the regression coefficient and covariate for the number of competitors, $a_{i}$ is the additive direct genetic value for animal $i$, $\mathrm{c}_{\mathrm{k}_{1}}+\ldots+\mathrm{c}_{\mathrm{k}_{\mathrm{N}}}$ are the genetic competition effects of other animals in the same pen (with a similar set for models with permanent environment competition effects), $\mathrm{p}_{\mathrm{k}}$ is the kth pen effect (fixed or random), and $e_{i k}$ is the residual effect.

The dispersion parameters are similar to those for a maternal effects model. Let a be the vector of additive direct genetic values augmented for animals in the relationship variance and $\mathrm{c}$ be the vector of additive competition genetic values augmented for animals in the relationship matrix. Then, $\mathrm{V}\left(\begin{array}{l}\mathrm{a} \\ \mathrm{c}\end{array}\right)=\mathrm{G}_{0} \otimes \mathrm{A}$, where $\mathrm{A}$ is the augmented relationship matrix, $\otimes$ is the right, direct product operator, and

$$
\mathrm{G}_{0}=\left(\begin{array}{cc}
\sigma_{\mathrm{d}}^{2} & \sigma_{\mathrm{dc}} \\
\sigma_{\mathrm{dc}} & \sigma_{\mathrm{c}}^{2}
\end{array}\right), \text { with }
$$

$\sigma_{\mathrm{d}}^{2}$, the direct genetic variance; $\sigma_{\mathrm{c}}^{2}$, the competition genetic variance; and $\sigma_{\mathrm{dc}}$, the direct-competition genetic covariance (for models without covariance this becomes zero).
For the model with a vector of competition permanent environmental effects, the variance structure is $\mathrm{I}_{\mathrm{Ne}} \sigma_{\text {pe }}^{2}$, where $I_{\mathrm{Ne}}$ is an identity matrix of order the total number of animals with observations, and $\sigma_{\mathrm{pe}}^{2}$ is the variance of competition permanent environmental effects. When the vector of pen effects is considered to be a vector of random effects, $\mathrm{V}(\mathrm{p})=\mathrm{I}_{\mathrm{Np}} \sigma_{\mathrm{p}}^{2}$, with $\mathrm{N}_{\mathrm{p}}$ the number of pens, and $\sigma_{\mathrm{p}}^{2}$ the pen component of variance. As usual, the residuals (vector e) are assumed uncorrelated with $\mathrm{V}(\mathrm{e})=\mathrm{I}_{\mathrm{N}} \sigma_{\mathrm{e}}^{2}$, with $\mathrm{N}$ the number of observations and $\sigma_{\mathrm{e}}^{2}$ the variance of residual effects. See Van Vleck and Cassady (2005) for a matrix representation of a similar model and the mixed model equations multiplied by $\sigma_{\mathrm{e}}^{2}$. The vector of permanent environmental competition effects would be added to their model and mixed model equations.

The competition genetic effect has also been analyzed with a classic random regression model, with the competition effects weighted by a 1 or a factor related to the number in the pen (e.g., see Arango et al., 2005, who used the BLUPF90 family of programs with such a model).

The full pedigree file for the selection experiment was available and consisted of a total of 3,649 animals from which the inverse of the numerator relationship matrix was computed for use in the augmented mixed model equations (Henderson, 1976).

The modified MTDFREML programs (Boldman et al., 1995) were used to estimate (co)variance components and to calculate -2 times the logarithm of the likelihood $(-2 \log \mathbf{L})$ given the data. To compare models with differ- 
ent random factors, care was taken to insure that the same constraints were used for all models with the same fixed factors. In only a limited number of cases was that actually necessary, as discussed later. Convergence was declared for a set of beginning values when the variance of the $-2 \log \mathrm{L}$ in the simplex was less than 0.000001 and estimates of parameters did not change in the first 2 decimal places.

For some models for ADG1, different beginning values for variance components were used with the derivative-free algorithm (Smith and Graser, 1986; Graser et al., 1987) to help insure that a global minimum for $-2 \log \mathrm{L}$ was found or to show that for certain models estimates of direct and competition (co)variances could not be separated.

Numerator relationships across lines imply that fixed line effects may not be necessary to include in the model. Therefore, for ADG1, the analyses were done with and without line as a fixed factor in the model.

\section{RESULTS AND DISCUSSION}

\section{Fit of Models (-2logL)}

Exploratory analyses to determine the fit of 18 models to the data for ADG1,...,ADG8 and for initial BW with fit being measured as $-2 \operatorname{logL}$ (smaller being better) are shown in Table 2. The first 9 models did not include initial BW as a covariate, and the second 9 models did. The patterns of $-2 \log \mathrm{L}$ were the same with or without initial BW as a covariate. The second and fourth blocks of analyses considered pen as a fixed rather than a random factor. The patterns of $-2 \log \mathrm{L}$ were also the same for these sets of 3 analyses with pen as a fixed factor.

A most important result (which may or may not be generalized to other designs and relationship structures) was that with pen as a fixed factor, the $-2 \log \mathrm{L}$ were the same for analyses with 3 models: direct genetic effects only, direct and competition genetic effects jointly, and joint genetic effects with nonzero genetic correlation (genetic covariance). Different beginning values did not always return the same estimates at convergence but did always result in the same $-2 \log L$. Such a result also may indicate a flat likelihood when pen is in the model as a fixed factor. Generally, as will be seen in Table 3, the estimates of direct genetic variance and residual variance changed less than estimates of competition genetic variance and direct-competition genetic covariance, but many combinations of direct and competition genetic variances and directcompetition genetic covariance could result in the same $-2 \log \mathrm{L}$ at convergence.

This result is disappointing in that initial inspection of simulation results (Van Vleck and Cassady, 2004c, 2005) suggested that analyses with pens as fixed effects would result in much smaller standard errors for the estimates of genetic competition parameters (variance and covariance). Closer inspection of the $-2 \log \mathrm{L}$ from their simulation results rather than just the means and SD from the 400 simulated replicates revealed the same result as shown here. In all cases, the corresponding 3 models for analysis with pens as fixed effects resulted in the same $-2 \log \mathrm{L}$ for each replicate and, of course, for the mean of 400 replicates. The smaller standard errors and mean estimates near the initial parameters used for simulation appear to have been an artifact of using parameter values as beginning values to speed convergence. Even though convergence was not to the beginning values, the likelihood surface, although flat, seemed to allow convergence near the beginning values. Restarts of those models with beginning values different from the parameter values resulted in the same $-2 \log \mathrm{L}$ but also with different apparent estimates of the parameters as also happened here with real data.

The $-2 \log \mathrm{L}$ values for models with pen as a random factor show a similar pattern with different random effects in the model for the 6 analyses without the covariate of initial BW and the 6 analyses with the initial BW covariate (not shown). Interpretation of the $-2 \log L$ is difficult because of possible choices of nesting of models. What is clear is that all other models had a better fit than the model with only a direct genetic effect for all traits. For ADG1, the model with direct and competition effects was superior to the model with direct and pen effects, but the direct, competition, and pen model had essentially the same $-2 \log \mathrm{L}$ as the model with direct and competition genetic effects. In most cases, the model with covariance between direct and competition genetic effects provided a better, but not significantly better, fit than the model with direct and competition genetic effects without the covariance, which could be due to a negligible covariance or because the data were insufficient to obtain an estimate that is statistically significant.

What the -2logL values with pen ignored as a random factor generally show is that an analysis model with competition effects results in a better fit, although not usually a significantly better fit, than models without the competition effect. The better fit implies that analyses with enough data and actual effects could result in significant estimates of competition parameters even if the magnitude of the parameter is small with this model but not necessarily for the random regression model used by Arango et al. (2005) for ADG of swine.

For ADG3,.., 6, the analyses with direct genetic effects as the only random factor led to automatic constraints for line and year effects, which were sometimes different for more complex models. When the same constraints were forced on the line and year effects, however, the $-2 \log L$ did not change.

The only analyses for which different constraints resulted in different $-2 \log \mathrm{L}$ were those with pen fixed. With direct genetic effects as the only random factor, the covariate for number of competitors was automatically constrained. When the constraints for the analysis model with direct genetic effects only were changed to be the same levels for line and year, then the $-2 \log \mathrm{L}$ 
Table 3. Estimates of $(\mathrm{co})$ variance components for 6 models $^{1}$ for ADG $(\mathrm{kg} \times 100)$ from initial BW through the end of periods 1 through $8^{2}$

\begin{tabular}{|c|c|c|c|c|c|c|c|c|c|}
\hline Model & Component $^{3}$ & 1 & 2 & 3 & 4 & 5 & 6 & 7 & 8 \\
\hline \multirow[t]{2}{*}{1} & $\sigma_{\mathrm{d}}^{2}$ & 119.33 & 45.23 & 48.88 & 47.23 & 51.93 & 46.10 & 53.16 & 31.43 \\
\hline & $\sigma_{\mathrm{e}}^{2}$ & 749.24 & 276.36 & 160.06 & 126.03 & 108.72 & 97.25 & 93.89 & 93.31 \\
\hline \multirow[t]{3}{*}{2} & $\sigma_{\mathrm{d}}^{2}$ & 32.73 & 31.94 & 38.10 & 44.07 & 48.19 & 42.72 & 39.70 & 25.73 \\
\hline & $\sigma_{\mathrm{c}}^{2}$ & 2.67 & 1.29 & 0.62 & 0.32 & 0.24 & 0.22 & 0.48 & 0.21 \\
\hline & $\sigma_{\mathrm{e}}^{2}$ & 736.50 & 256.63 & 152.48 & 120.20 & 105.26 & 93.47 & 91.60 & 92.89 \\
\hline \multirow[t]{4}{*}{3} & $\sigma_{\mathrm{d}}^{2}$ & 48.28 & 43.57 & 41.23 & 44.79 & 47.81 & 42.35 & 42.49 & 28.17 \\
\hline & $\sigma_{\mathrm{c}}^{2}$ & 2.25 & 0.93 & 0.47 & 0.26 & 0.17 & 0.17 & 0.36 & 0.11 \\
\hline & $\sigma_{\mathrm{dc}}$ & 7.14 & 5.71 & 2.46 & 1.04 & 1.33 & 1.07 & 2.13 & 1.73 \\
\hline & $\sigma_{\mathrm{e}}^{2}$ & 735.00 & 256.51 & 153.72 & 121.27 & 107.21 & 95.21 & 92.63 & 93.86 \\
\hline \multirow[t]{3}{*}{4} & $\sigma_{\mathrm{d}}^{2}$ & 36.20 & 32.99 & 38.52 & 43.83 & 47.08 & 42.60 & 40.55 & 26.30 \\
\hline & $\sigma_{\mathrm{p}}^{2}$ & 103.56 & 36.48 & 19.84 & 10.04 & 8.38 & 7.90 & 15.71 & 6.87 \\
\hline & $\sigma_{\mathrm{e}}^{2}$ & 734.67 & 255.91 & 152.18 & 120.65 & 106.00 & 93.68 & 91.32 & 92.57 \\
\hline \multirow[t]{4}{*}{5} & $\sigma_{\mathrm{d}}^{2}$ & 33.67 & 33.36 & 38.76 & 43.78 & 47.40 & 42.41 & 40.21 & 26.16 \\
\hline & $\sigma_{\mathrm{c}}^{2}$ & 2.09 & 0.00 & 0.11 & 0.05 & 0.07 & 0.09 & 0.16 & 0.03 \\
\hline & $\sigma_{\mathrm{p}}^{2}$ & 18.05 & 36.43 & 15.51 & 8.53 & 5.58 & 4.60 & 10.10 & 5.87 \\
\hline & $\sigma_{\mathrm{e}}^{2}$ & 735.81 & 255.90 & 151.76 & 120.67 & 105.53 & 93.73 & 91.35 & 92.69 \\
\hline \multirow[t]{5}{*}{6} & $\sigma_{\mathrm{d}}^{2}$ & 47.85 & 35.39 & 39.98 & 43.74 & 47.66 & 42.02 & 41.98 & 27.13 \\
\hline & $\sigma_{\mathrm{c}}^{2}$ & 2.23 & 0.06 & 0.12 & 0.05 & 0.08 & 0.08 & 0.14 & 0.04 \\
\hline & $\sigma_{\mathrm{dc}}$ & 7.17 & 1.43 & 1.25 & 0.10 & 0.77 & 0.67 & 1.63 & 1.02 \\
\hline & $\sigma_{\mathrm{p}}^{2}$ & 0.02 & 31.77 & 13.26 & 8.39 & 4.13 & 3.69 & 7.85 & 3.80 \\
\hline & $\sigma_{\mathrm{e}}^{2}$ & 732.32 & 255.96 & 152.84 & 120.60 & 106.54 & 94.80 & 92.35 & 92.89 \\
\hline
\end{tabular}

${ }^{1}$ Fixed effects of models also included linear covariates for calendar day of birth and number of competitors, selection line (4), and year of birth (8).

${ }^{2}$ Periods 1 through 7 were $28 \mathrm{~d}$, and the eighth period was usually less than $28 \mathrm{~d}$.

${ }^{3} \sigma_{\mathrm{d}}^{2}=$ direct genetic variance, $\sigma_{\mathrm{c}}^{2}=$ competition genetic variance, $\sigma_{\mathrm{p}}^{2}=$ pen variance, $\sigma_{\mathrm{e}}^{2}=$ residual variance, and $\sigma_{\mathrm{dc}}=$ direct-competition genetic covariance.

were the same for the 3 analyses with initial BW as a covariate. Similarly, for the 3 analyses with initial BW ignored the $-2 \log \mathrm{L}$ were the same.

Based on the exploratory analyses, only analyses with initial BW as a covariate and with pen random or ignored will be reported for ADG. Blank lines in Table 2 separate the models for analyses for 6 combinations of random factors. The corresponding $-2 \log \mathrm{L}$ also are in Table 2.

The pattern for results in Table 3 suggests that competition genetic effects existed for ADG1 although with relatively small estimates of the variance component. What is also apparent is that for several models the variance due to competition effects declines steadily with additional periods included in ADG. For example, ADG2 is basically the average of gains in periods 1 and 2 . Thus the estimates of the variance components due to competition effects for ADG2,...,ADG8 essentially suggest that competition effects were present only for period 1 with estimates of competition variance in cumulative periods due to carryover effects from period 1. Such a result suggests that genetic determination of competition effects changes over time, possibly due to adaptation of animals in a pen to each other.

Similarly, for models with random pen effects, the estimates of variance due to pen effects generally de- creased with gain averaged over more periods with some exceptions.

For ADG1, the analysis model with direct and competition genetic effects fit better than the model with direct genetic and pen effects. In fact, comparison of the model with $\mathrm{D}, \mathrm{C}$, and $\mathrm{P}$ effects with the model with $\mathrm{D}$ and $\mathrm{C}$ effects showed that pen effects did not contribute to a better fit for the model. Comparison of the model with $\mathrm{D}, \mathrm{C}$, and $\mathrm{P}$ with the model with $\mathrm{D}$ and $\mathrm{P}$ showed a significant $(P<0.05)$ contribution of competition genetic effects to fit of the model for ADG1.

The pattern for ADG through later periods was reversed from that for ADG1 with the $\mathrm{D}$ and $\mathrm{P}$ model fitting better than the $\mathrm{D}$ and $\mathrm{C}$ model with a generally similar fit for the D and P model and the D, C, and P model but with differences not approaching significance $(P>0.05)$. Except for ADG1, the fit of the full model was not significantly better than the fit of the $\mathrm{D}$ and P model.

The patterns for estimates with increasing number of periods in ADG were similar for most models including those with both $\mathrm{C}$ and $\mathrm{P}$ factors. For those models, estimates of competition genetic variance, $\sigma_{\mathrm{c}}^{2}$, were essentially zero after the first period. Estimates of pen and residual variances, $\sigma_{\mathrm{p}}^{2}$ and $\sigma_{\mathrm{e}}^{2}$, generally decreased substantially as number of periods included in ADG 
Table 4. Estimates of (co)variance components from analyses of initial BW (kg) with 9 models ${ }^{1}$ used for ADG

\begin{tabular}{lcccccc}
\hline \hline & \multicolumn{5}{c}{ (Co)variance component ${ }^{2}$} \\
\cline { 2 - 7 } Model & $\sigma_{\mathrm{d}}^{2}$ & $\sigma_{\mathrm{c}}^{2}$ & $\sigma_{\mathrm{dc}}$ & $\sigma_{\mathrm{p}}^{2}$ & $\sigma_{\mathrm{e}}^{2}$ & $-2 \operatorname{logL}$ \\
\hline 1 & 229.82 & - & - & - & 581.44 & 362.78 \\
2 & 231.30 & 0.00 & - & - & 580.78 & 362.78 \\
3 & 279.65 & 0.06 & -3.98 & - & 544.42 & 360.04 \\
4 & 230.71 & - & - & 0.00 & 580.50 & 362.78 \\
5 & 230.14 & 0.00 & - & 0.00 & 580.98 & 362.78 \\
6 & 269.38 & 0.04 & -3.24 & 0.00 & 550.13 & 360.14 \\
7 & 221.41 & - & - & Fix & 594.14 & 107.52 \\
8 & 220.51 & 0.46 & - & Fix & 594.58 & 107.52 \\
9 & 203.95 & 3.53 & -6.98 & Fix & 594.58 & 107.52 \\
\hline
\end{tabular}

${ }^{1}$ The fixed effects portion of the model also included covariates for calendar day of birth and number of competitors, selection line (4), and year of birth (8). A numerical value in a column indicates that the effect was in the model, and a dash indicates that the effect was not in the model; Fix = fixed pen effect.

${ }^{2} \sigma_{\mathrm{d}}^{2}=$ direct genetic variance, $\sigma_{\mathrm{c}}^{2}=$ competition genetic variance, $\sigma_{\mathrm{p}}^{2}=$ pen variance, $\sigma_{\mathrm{e}}^{2}=$ residual variance, $\sigma_{\mathrm{dc}}=$ direct-competition genetic covariance, and $-2 \log \mathrm{L}=$ minus twice the logarithm of the likelihood given the data $-14,000$.

increased as expected for variables that are little to moderately correlated from period to period. Estimates of direct genetic variance, $\sigma_{\mathrm{d}}^{2}$, were similar for ADG2 to ADG7 and actually increased somewhat as number of periods increased. The similarity of estimates over periods may be due to genetic correlations of near unity among gains in different periods. The net effect was larger estimates of heritability for ADG accumulated over more periods.

\section{Analyses of Initial BW}

As a test of the ability of the models to separate variance due to direct and competition genetic effects and pen effects, the same models as used for ADG were used for initial BW, which would not yet include pen or competition effects. Those analyses are summarized in Table 4. The last 3 rows again demonstrate the problem when pens are considered to be fixed effects. The analyses shown by the top 6 rows of Table 4 resulted in near zero estimates of variance due to competition and pen effects with identical likelihoods for all models except those including a covariance between direct and competition genetic effects for which the large negative estimates seem unrealistic. The reason why including pen as a fixed effect seems to result in unrealistic estimates of variance and covariance of genetic competition effects is not obvious. The reasons may include some mathematical artifact due to the model or data structure but seem more likely to be due to a high level of confounding between pen effects and effects of competitors within the pen (Van Vleck and Cassady, 2004b).

For ADG1, the estimates of direct-competition genetic covariances in Table 3 were also large but positive and with larger estimates for competition genetic variance. None of the differences in likelihoods were significant $(P>0.05)$ for the covariances between direct and competition genetic effects for analyses summarized in Tables 3 and 4.
Comparison of results in Table 4 with those in Table 3 suggest for ADG that pen effects are important and that competition effects may be present for ADG1.

\section{Effects of Selection Line Not in Model}

With animals in lines related through common foundation parents, those relationships should account for differences in lines due to selection. Table 5 summarizes analyses of ADG1 for models with line effects ignored (first 6 rows) and with line effects in the model (last 6 rows). The patterns for results are similar for the 2 sets of analyses with similar differences in $-2 \log L$ for the various models. For most models, estimates of $\sigma_{\mathrm{d}}^{2}$ were larger with line effects ignored and accounted for through numerator relationships. Estimates of $\sigma_{\mathrm{c}}^{2}$, however, were somewhat smaller with line effects ignored. Estimates of direct-competition genetic correlations were approximately 0.66 for all analyses including the direct-competition covariance. Estimates of $\sigma_{\mathrm{e}}^{2}$ were slightly smaller for the models with lines not included as fixed effects, although estimates of $\sigma_{\mathrm{p}}^{2}$ were slightly larger for models with random pen effects than for models with lines included as fixed effects. These comparisons suggest for this data structure that ignoring line effects makes little difference. The larger estimates of direct genetic variance and the smaller estimates of residual variance may favor the models that ignore line effects.

\section{Analyses with Repeated Competition Effects}

The model for a competition effect should include a genetic plus an environmental effect. Such environmental effects also would be embedded in the record of each pen mate and would create nongenetic covariances among records of pen mates. As with previous studies of competition effects, the analyses shown in Tables 2 through 5 considered only the genetic competition ef- 
Table 5. Estimates of (co)variance components for models with and without line as a fixed factor for ADG $(\mathrm{kg} \times 100)$ for period 1

\begin{tabular}{|c|c|c|c|c|c|c|}
\hline \multirow[b]{2}{*}{ Model $^{1}$} & \multicolumn{6}{|c|}{ (Co)variance component ${ }^{2}$} \\
\hline & $\sigma_{\mathrm{d}}^{2}$ & $\sigma_{\mathrm{c}}^{2}$ & $\sigma_{\mathrm{dc}}$ & $\sigma_{\mathrm{p}}^{2}$ & $\sigma_{\mathrm{e}}^{2}$ & $-2 \log \mathrm{L}$ \\
\hline & \multicolumn{6}{|c|}{ Without line in model- } \\
\hline 1 & 139.46 & - & - & - & 735.26 & 533.79 \\
\hline 2 & 35.99 & 2.57 & - & - & 734.64 & 421.71 \\
\hline 3 & 48.55 & 2.14 & 6.74 & - & 733.97 & 420.10 \\
\hline 4 & 53.36 & - & - & 108.08 & 721.97 & 425.93 \\
\hline 5 & 36.01 & 1.52 & - & 34.74 & 734.19 & 421.10 \\
\hline 6 & 46.61 & 1.50 & 5.67 & 21.50 & 734.03 & 419.89 \\
\hline 7 & 119.33 & - & - & - & 749.24 & 519.92 \\
\hline 8 & 32.73 & 2.67 & - & - & 736.50 & 406.40 \\
\hline 9 & 48.28 & 2.25 & 7.14 & - & 735.00 & 404.88 \\
\hline 10 & 36.20 & - & - & 103.56 & 734.67 & 410.57 \\
\hline 11 & 33.67 & 2.09 & - & 18.05 & 735.81 & 406.25 \\
\hline 12 & 47.85 & 2.23 & 7.17 & 0.02 & 735.32 & 404.88 \\
\hline
\end{tabular}

${ }^{1}$ The fixed effects portion of the model also included covariates for date of birth, number of competitors, initial BW, and fixed factor for year of birth (8). A numerical value in a column indicates that the effect was in the model, and a dash indicates the effect was not in the model.

${ }^{2} \sigma_{\mathrm{d}}^{2}=$ direct genetic variance, $\sigma_{\mathrm{c}}^{2}=$ competition genetic variance, $\sigma_{\mathrm{p}}^{2}=$ pen variance, $\sigma_{\mathrm{e}}^{2}=$ residual variance, $\sigma_{\mathrm{dc}}=$ direct-competition genetic covariance, and $-2 \log \mathrm{L}=$ minus twice the logarithm of the likelihood given the data $-14,000$.

fect. One way to model the repeated environmental effects would be to include an uncorrelated random effect associated with a competitor in the record of each of the competitor's pen mates. The model would be somewhat equivalent to a repeated records model but with the repeated effect being associated with a competitor rather than with the animal or the dam of the animal with a record. A competitor would contribute genetic and environmental competition effects to records of pen mates, but the environmental competition effects would be uncorrelated and not tied together through relationships.

The environmental competition effects would contribute to covariance between records of pen mates as would the genetic competition effects but may have an even larger effect depending on the magnitude of genetic and environmental variances. Covariances between pen mates due to competition effects may contribute to variance due to pen effects even if true pen effects are zero (Van Vleck and Cassady, 2004c, 2005) if competition effects exist and are ignored. Such effects also would contribute other large blocks of nonzero elements in the coefficient matrix of the mixed model equations.

The MTDFREML programs were modified to include competition environmental effects as well as genetic competition effects. Table 6 summarizes estimates of variance components for ADG1 for models ignoring line effects with some models including competition genetic and environmental effects (models 1 and 3) and joint direct genetic and environmental competition effects ignoring competition genetic effects (models 2 and 4). Models 1 and 2 show that accounting for genetic and environmental competition effects separately or jointly even when the estimates of variance components are small reduces the estimates of pen variance to near zero. Models 5 through 7 without the competition environmental effects have larger (poorer) -2logL. Models 6 and 7, with pen effects, have large estimates of variance due to pen effects. These results suggest for ADG1 that the embedded competition effects (genetic and environmental) account for most or nearly all of what would usually be termed variance due to pen effects for traditional models having as random effects only direct genetic and pen effects. Summaries of estimates of variance components for ADG1 through ADG6 in Table 7 show that the embedded genetic and environmental competition effects generally account for essentially all of the variance of pen effects even though estimates of these variances are small after the first or second period.

The estimates of variance components suggest that competition genetic and competition environmental effects affected ADG for the first $28 \mathrm{~d}$ in the feedlot for these Hereford bulls under the conditions of their feeding trials. Although an estimate of the fraction of variance due to competition genetic effects is small, the index BW for an animal for direct and competition genetic effects (estimated as $\hat{\mathrm{d}}$ and $\hat{\mathrm{c}}$ ) are 1 and $\mathrm{n}-1$ where $\mathrm{n}$ is the number of animals in a pen, which make even a small fraction of variance important:

$$
I=\hat{d}+(n-1) \hat{c} .
$$

Thus, even with only a small variance associated with genetic competition effects, genetic competition effects can be important economically. For example, from the estimates of variance components for the full model in Table 6, then $\sigma_{\mathrm{d}}=\sqrt{36.96}=6.08$ and $\sigma_{\mathrm{c}_{\mathrm{g}}}=\sqrt{1.10}=1.05$. 
Table 6. Comparison of estimates of variance components for models ${ }^{1}$ without line effects for ADG in period $1(\mathrm{~kg} \times 100)$, including models with and without competition permanent environmental effects

\begin{tabular}{lcccccc}
\hline \hline & \multicolumn{5}{c}{ Estimate of variance component } \\
\cline { 2 - 7 } Model $^{2}$ & $\sigma_{\mathrm{d}}^{2}$ & $\sigma_{\mathrm{c}_{\mathrm{g}}}^{2}$ & $\sigma_{\mathrm{c}}^{2}$ & $\sigma_{\mathrm{p}}^{2}$ & $\sigma_{\mathrm{e}}^{2}$ & $-2 \operatorname{logL}$ \\
\hline 1 & 36.96 & 1.10 & 1.78 & 0.01 & 731.67 & 420.23 \\
2 & 54.24 & - & 3.77 & 0.04 & 716.68 & 423.92 \\
3 & 37.10 & 1.11 & 1.77 & - & 731.75 & 420.23 \\
4 & 53.94 & - & 3.78 & - & 716.31 & 423.92 \\
5 & 35.99 & 2.57 & - & - & 734.64 & 421.71 \\
6 & 53.36 & - & - & 108.08 & 721.97 & 425.93 \\
7 & 36.01 & 1.52 & - & 34.74 & 734.19 & 421.10 \\
\hline
\end{tabular}

${ }^{1}$ The fixed effects for all models included linear covariates for date of birth, number of competitors, initial BW, and a fixed factor for year of birth (8). A dash in the estimate of variance component column indicates that the effect was not in the model.

${ }^{2} \sigma_{\mathrm{d}}^{2}=$ direct genetic variance, $\sigma_{c_{g}}^{2}=$ competition genetic variance, $\sigma_{c e}^{2}=$ competition permanent environmental variance, $\sigma_{\mathrm{p}}^{2}=$ pen variance, $\sigma_{\mathrm{e}}^{2}=$ residual variance, and $-2 \log \mathrm{L}=$ minus twice the logarithm of the likelihood given the data $-14,000$.

If gains for selection were 1 genetic SD for direct and competition genetic values, then with 30 bulls per pen, the economic gain would be: $\Delta \mathrm{I}=(6.08)+29(1.05)=$ $6.08+30.45$ with most of the gain from competition rather than direct genetic effects. Thus, one problem is how to decide how much emphasis to give to statistical significance of components of variance $(P<0.05)$ and how much emphasis to give potential economic gain. With these data, that question becomes less important because by the end of the fifth or sixth periods (or even the second period; models 5 and 6 , Table 3), the SD for genetic competition effects for $\mathrm{ADG}$ becomes quite small.

In still another way, deciding which is the appropriate model with competition effects is not entirely a statistical problem. If a model with competition effects and a model with pen effects fit the data equally well as was the case for most time periods in this study, then predictions of breeding value for the direct genetic effect may be equally accurate with both models. But if competition effects exist and are to be selected for, then the question of which model to use when statistical significance cannot be obtained is not easy to answer. A way to a possible answer might be to obtain more data with a relationship structure that would allow separation of competition and other pen effects (e.g., Van Vleck, 2005). Such data are not easy to obtain, and the pen structure and number of pen mates also need to be comparable for the previous and future data. Arango et al. (2005) have discussed the problems with obtaining data that might exhibit similar competition effects.

Although earlier simulation studies suggested models with pens as fixed effects would reduce standard errors of estimates of competition variances, reexamination of those results and results from these analyses show that when pens are treated as fixed effects, the direct and competition variances and covariance cannot

Table 7. Estimates of variance components for ADG $(\mathrm{kg} \times 100)$ for period 1 through 6 (periods of $28 \mathrm{~d}$ ) for models without line effects and including random pen and genetic and permanent environmental competition effects ${ }^{1}$

\begin{tabular}{|c|c|c|c|c|c|c|}
\hline \multirow{2}{*}{$\begin{array}{l}\text { Estimated } \\
\text { variance } \\
\text { component }^{2}\end{array}$} & \multicolumn{6}{|c|}{ Period } \\
\hline & 1 & 2 & 3 & 4 & 5 & 6 \\
\hline$\sigma_{\mathrm{d}}^{2}$ & 36.96 & 35.15 & 40.02 & 47.42 & 50.38 & 44.00 \\
\hline$\sigma_{c_{g}}^{2}$ & 1.10 & 0.09 & 0.09 & 0.06 & 0.09 & 0.10 \\
\hline$\sigma_{c e}^{2}$ & 1.78 & 1.23 & 0.60 & 0.30 & 0.18 & 0.16 \\
\hline$\sigma_{\mathrm{p}}^{2}$ & 0.01 & 0.00 & 0.00 & 0.00 & 0.33 & 0.00 \\
\hline$\sigma_{\mathrm{e}}^{2}$ & 731.67 & 252.99 & 150.37 & 117.68 & 103.40 & 92.23 \\
\hline
\end{tabular}

${ }^{1}$ The fixed effects in the model included linear covariates for calendar day of birth, number of competitors, initial BW, and fixed factor for year (8).

${ }^{2} \sigma_{\mathrm{d}}^{2}=$ direct genetic variance, $\sigma_{c_{g}}^{2}=$ competition genetic variance, $\sigma_{c_{p e}}^{2}=$ competition permanent environmental variance, $\sigma_{\mathrm{p}}^{2}=$ pen variance, and $\sigma_{\mathrm{e}}^{2}=$ residual variance. 
be separated. Whether this result is true for all designs is not known.

\section{LITERATURE CITED}

Arango, J., I. Misztal, S. Tsuruta, M. Culbertson, and W. Herring. 2005. Estimation of variance components including competitive effects of Large White growing gilts. J. Anim. Sci. 83:1241-1246.

Boldman, K. G., L. A. Kriese, L. D. Van Vleck, C. P. Van Tassell, and S. D. Kachman. 1995. A manual for use of MTDFREML. A set of programs to obtain estimates of variance and covariances [Draft]. USDA-ARS, Clay Center, NE.

Federer, W. T. 1955. Experimental design: Theory and application. The MacMillan Company, New York, NY.

Graser, H.-U., S. P. Smith, and B. Tier. 1987. A derivative-free approach for estimating variance components in animal models by restricted maximum likelihood. J. Anim. Sci. 64:1362-1370.

Griffing, B. 1967. Selection in reference to biological groups. I. Individual and group selection applied to populations of unordered groups. Aust. J. Biol. Sci. 10:127-139.

Henderson, C. R. 1976. A simple method for computing the inverse of a numerator relationship matrix used in prediction of breeding values. Biometrics 32:69-83.

Koch, R. M., L. V. Cundiff, and K. E. Gregory. 1974a. Selection in beef cattle. I. Selection applied and generation interval. J. Anim. Sci. 39:449-458.
Koch, R. M., L. V. Cundiff, and K. E. Gregory. 1974b. Selection in beef cattle. II. Selection response. J. Anim. Sci. 39:459-470.

Koch, R. M., L. V. Cundiff, and K. E. Gregory. 1994. Cumulative selection and genetic change for weaning and yearling weight plus muscle score in Hereford cattle. J. Anim. Sci. 72:864-885.

Muir, W. M., and A. Schinckel. 2002. Incorporation of competitive effects in breeding programs to improve productivity and animal well being. Proc. 7th World Congr. Genet. Appl. Livest. Prod. CD-ROM Communication No. 14-07. Montpellier, France.

Smith, S. P., and H.-U. Graser. 1986. Estimating variance components in a class of mixed models by restricted maximum likelihood. J. Dairy Sci. 69:1156-1165.

Van Vleck, L. D. 2005. Three designs for estimating variances due to competition genetic effects. J. Anim. Sci. 83(Suppl.1):6. (Abstr.)

Van Vleck, L. D., and J. P. Cassady. 2004a. Modification of MTDFREML to estimate variance due to genetic competition effects. J. Anim. Sci. 82(Suppl.2):38. (Abstr.)

Van Vleck, L. D., and J. P. Cassady. 2004b. Random models with direct and competition genetic effects. Pages 17-30 in Proc. 16th Annu. Kansas State Univ. Conf. Appl. Stat. Agric. Manhattan, KS, April 25-27, 2004.

Van Vleck, L. D., and J. P. Cassady. 2004c. Unexpected estimates of variance components with a true model containing genetic competition effects. J. Anim. Sci. 82(Suppl.1):84. (Abstr.)

Van Vleck, L. D., and J. P. Cassady. 2005. Unexpected estimates of variance components with a true model containing genetic competition effects. J. Anim. Sci. 83:68-74. 